University of Nebraska - Lincoln

DigitalCommons@University of Nebraska - Lincoln

\title{
The Role of Cholecystokinin in the Expression of Seasonal Variation in the Feed Intake and Eating Pattern of Red Deer (Cervus elaphus)
}

S. M. Rhind

Macaulay Land Use Research Institute, s.rhind@mluri.sari.ac.uk

S. R. McMillen

Macaulay Land Use Research Institute

J. C. Pekas

USDA-ARS

E. Duff

Macaulay Land Use Research Institute

Follow this and additional works at: https://digitalcommons.unl.edu/hruskareports

Rhind, S. M.; McMillen, S. R.; Pekas, J. C.; and Duff, E., "The Role of Cholecystokinin in the Expression of Seasonal Variation in the Feed Intake and Eating Pattern of Red Deer (Cervus elaphus)" (2001). Roman L. Hruska U.S. Meat Animal Research Center. 249.

https://digitalcommons.unl.edu/hruskareports/249

This Article is brought to you for free and open access by the U.S. Department of Agriculture: Agricultural Research Service, Lincoln, Nebraska at DigitalCommons@University of Nebraska - Lincoln. It has been accepted for inclusion in Roman L. Hruska U.S. Meat Animal Research Center by an authorized administrator of DigitalCommons@University of Nebraska - Lincoln. 


\title{
The role of cholecystokinin in the expression of seasonal variation in the feed intake and eating pattern of red deer (Cervus elaphus)
}

\author{
S.M. Rhind ${ }^{\mathrm{a}, *}$, S.R. McMillen ${ }^{\mathrm{a}}$, J.C. Pekas ${ }^{\mathrm{b}}$, E. Duff ${ }^{\mathrm{c}}$ \\ a Macaulay Land Use Research Institute, Craigiebuckler, Aberdeen, Scotland AB15 8QJ, UK \\ ${ }^{\mathrm{b}}$ USDA, ARS, R.L. Hruska Meat Animal Research Center, Clay Center, NE, 68933-0166, USA \\ ${ }^{\mathrm{c}}$ Biomathematics and Statistics Scotland, Macaulay Land Use Research Institute, Craigiebuckler, Aberdeen, Scotland AB15 8QJ, UK
}

Received 8 January 2001; received in revised form 5 February 2001; accepted 2 March 2001

\begin{abstract}
The role of cholecystokinin (CCK) in the expression of seasonal variation in feed intake and feeding activity in ruminants was investigated by active immunisation of castrated male red deer (Cervus elaphus). In April, animals of two groups (five animals per group) were immunised against either CCK or vehicle solution only and booster injections were administered at 2-month intervals for the following year. Measurements were conducted for a period of more than a year from July. There were no significant effects of immunisation on mean daily food intake. However, there was a significant interaction $(P<.01)$ between immunisation and month (season), with respect to rate of feed ingestion during meals, with animals immunised against CCK exhibiting higher mean rates of ingestion during October to May but lower mean rates during June to September. It is concluded that systemic CCK has a role in the expression of seasonal variation in the rate of feed ingestion during meals in ruminants and that this, in turn, may affect the pattern of seasonal change in daily feed intake. Since there was no evidence of differences with treatment in profiles of insulin, growth hormone $(\mathrm{GH})$, thyroxine $\left(\mathrm{T}_{4}\right)$, triiodothyronine $\left(\mathrm{T}_{3}\right)$, insulin-like growth factor-1 (IGF-1) or prolactin, it is unlikely that this effect is expressed through changes in the profiles of these hormones. (C) 2001 Elsevier Science Inc. All rights reserved.
\end{abstract}

Keywords: Cholecystokinin; Season; Deer; Food intake; Hormones

\section{Introduction}

Red deer exhibit large seasonal variations in daily feed intake $[11,14]$, and a period of reduced intake during shortday photoperiod (winter) is associated with a reduction in growth rate [12], which, in farmed deer, is economically undesirable. Potentially, the reduction in mean daily feed intake under short-day photoperiod could be overcome by manipulation of the balance of the metabolic hormones that regulate eating patterns (meal size, meal duration, intermeal interval, and ingestion rate). One form of manipulation, immunisation against cholecystokinin (CCK), has been shown to induce a long-term increase in mean daily feed intakes in pigs [17,18], suggesting that this hormone is involved in the long-term regulation of eating pattern and

\footnotetext{
556.

* Corresponding author. Tel.: +44-1224-318-611; fax: +44-1224-311-

E-mail address: s.rhind@mluri.sari.ac.uk (S.M. Rhind).
}

level of daily feed intake. Studies of lambs [24], on the other hand, have failed to show such an increase in daily feed intake, suggesting that the physiological role of CCK differs with species.

The role of CCK in the expression of photoperiodinduced changes in meal patterns and rate of feed ingestion during meals, throughout the day, is unknown and the effect on these aspects of behaviour of immunisation against this hormone has not been investigated.

The first objective of this study was to determine the effect of immunisation against CCK on the mean daily feed intake and eating patterns of red deer at different seasons.

The effect of season on appetite and level of daily feed intake is mediated through changes in both meal pattern and rate of feed ingestion [20], and many humoral and neural factors, some of which operate in conjunction with CCK, have been implicated in the mediation of these processes of appetite regulation [9]. While some of the endocrine profiles associated with changes in eating pattern have been investigated, they are complex and their mechanisms of action 
remain poorly understood [20]. The effects of immunisation against CCK on these profiles and on the associated patterns of feeding behaviour and daily feed intake are unknown.

The second objective of the study was to determine the effect of immunisation against CCK on the profiles of metabolic hormones, which are considered likely to be involved in the regulation of feeding behaviour and feed intake and to assess their roles in these processes.

\section{Materials and methods}

\subsection{Experimental procedures}

Two similar groups of five adult, castrated, male red deer, aged approximately 2 years, were used. This type of animal was chosen because it exhibits a marked variation in feed intake, but the underlying endocrine control mechanisms are not confounded with changes in hormone profiles associated with reproductive cycles. The animals were housed in individual pens under natural daylength conditions at $57^{\circ} \mathrm{N}$ throughout a 15 -month study and fed ad libitum, to a refusal rate of 0.2 , on a complete diet based on barley, sugar beet pulp, dried grass pellets, and fish meal. It contained $880 \mathrm{~g} / \mathrm{kg}$ dry matter (DM) and an estimated 12.0 MJ of metabolisable energy (ME) and $160 \mathrm{~g}$ crude protein per kilogram of DM. Refusals were recorded daily and mean daily feed intakes were calculated.

Liveweights were recorded every 2 weeks during the study.

\subsection{Immunisation protocols}

Animals of one group were immunised against CCK (Immunised; I) before the study began. They were injected (subcutaneously over the brisket) with $1 \mathrm{mg}$ ovalbumin conjugated (using $0.2 \mathrm{ml}$ glutaraldehyde) to $0.5 \mathrm{mg}$ sulphated CCK-8 (Backem, Saffron Walden, Essex, UK) and 0.3 mg Coparvax (Corynebacterium parvum; Wellcome, London, UK) dissolved in $0.7 \mathrm{ml}$ distilled water. The conjugate was emulsified with $1.8 \mathrm{ml}$ Freund's incomplete adjuvant. Animals of the second group (Control; C) were treated with the same immunogen, except that the CCK was not included.

The priming injection was given in April and booster injections were given in May, June, July, August, and thereafter at intervals of approximately 2 months until the following June. Measurements of meal patterns and hormone profiles were commenced in July, 3 months after the priming injection, when it was anticipated that antibody titres would be elevated.

\subsection{Measurement of meal patterns}

Detailed information on patterns of feeding behaviour was collected at intervals of approximately 1 month. This was achieved by automated recording, to the nearest $10 \mathrm{~g}$, of the weight of food in the feed bins at 10-min intervals throughout a 4-day period. An intermeal interval was defined as a time during which there was no reduction in the weight of feed in the bin. From these records, the average meal durations and frequencies and rates of ingestion at each season were determined. (The relatively long interval of $10 \mathrm{~min}$ between records was selected because it was considered more likely to reflect a response to a physiological signal than, say, a 1- to 2-min interruption in feeding behaviour, which could be attributable to a transient distraction.)

\subsection{Blood sample collection}

Blood samples were collected from both immunised and control animals at intervals of approximately 2 months during the study, by jugular venipuncture, for the purpose of antibody titre determination. In addition, blood samples were collected every 2 weeks for the purpose of hormone determinations. Samples were collected before refilling of feed bins between 0800 and $1100 \mathrm{~h}$. Samples were collected at this time because it was considered likely that the circulating levels of metabolic hormones would be basal and relatively stable at this time, whereas rapid changes might be expected to follow the introduction of feed, despite the fact that the animals were fed ad libitum and were therefore not subject to periods of feed restriction.

\subsection{Antibody titre determination}

Samples were serially diluted seven times by 6.5 -fold to a maximum dilution of 1:490,223 and incubated with radiolabelled CCK. The titre was defined as the dilution at which $300 \mu \mathrm{l}$ of sample would specifically bind $50 \%$ of $1 \mathrm{fmol}$ of radiolabelled CCK.

\subsection{Hormone assays}

Sources of the assays used to measure circulating concentrations of insulin, growth hormone $(\mathrm{GH})$, thyroxine $\left(\mathrm{T}_{4}\right)$, triiodothyronine $\left(\mathrm{T}_{3}\right)$, prolactin, and insulin-like growth factor-1 (IGF-1) are given in Table 1, together with assay sensitivities and intra- and interassay coefficients of variation $(\mathrm{CV})$. All methods were validated for deer plasma

Table 1

Sources of insulin, $\mathrm{GH}, \mathrm{T}_{4}, \mathrm{~T}_{3}$, prolactin, and IGF-1 assay methods, reference preparations, assay sensitivities, and $\mathrm{CV}(\%)$

\begin{tabular}{lllll}
\hline & & \multicolumn{3}{c}{ Intra-assay } \\
Assay & Method & Sensitivity & CV (\%) & CV (\%) \\
\hline Prolactin & McNeilly and Andrews [15] & $0.1 \mathrm{ng} / \mathrm{ml}$ & 5.7 & - \\
$\mathrm{T}_{4}$ & Amerlex-M RIA kit & $4.0 \mathrm{nmol} / 1$ & 3.3 & 4.3 \\
$\mathrm{~T}_{3}$ & Amerlex-M RIA kit & $0.15 \mathrm{nmol} / 1$ & 4.6 & 4.9 \\
Insulin & MacRae et al. [16] & $2.6 \mathrm{mU} / 1$ & 9.1 & - \\
IGF-1 & Bruce et al. [3] & $0.24 \mu \mathrm{g} / 1$ & 8.8 & - \\
$\mathrm{GH}$ & Rhind et al. [20] & $0.63 \mu \mathrm{g} / 1$ & 11.8 & - \\
\hline
\end{tabular}


by demonstrating that measures of hormone concentrations in serially diluted samples, selected randomly, ran parallel with the standard curve.

\subsection{Statistical analyses}

\subsubsection{Meal patterns}

Data were analysed using Genstat 5 software [13]. To reduce the effects of random variation attributable, e.g., to vibration or 'electronic noise' in the feed weighing system, a decreasing monotonic regression (stepfunction) was fitted to the weights, according to the protocols described in detail previously [20]. The fitted values from the monotonic regression were used to derive summary statistics, describing the meal patterns, for each 4-day period.

Effects of treatment and month (season) on frequency of meals (eating bouts), meal lengths, meal sizes (weight of food consumed), intermeal intervals, percentage of time spent eating, and rates of food ingestion during meals $(\mathrm{g} /$ $\mathrm{min}$ ) and on hormone concentrations were determined using analysis of variance (ANOVA). The structure of the analysis was a nested design (animal, month within animal). Effects of immunisation were assessed at the animal level with month (season) and the interaction between month and immunisation being assessed in the lower stratum of the analysis [13]. When necessary, hormone concentration data were log-transformed prior to ANOVA to satisfy the requirement for constant variance in ANOVA.

\section{Results}

\subsection{Antibody titres}

All immunised animals exhibited CCK antibody titres greater than 1:100 by the time of the second reinforcing injection in August when measurements of feeding behaviour were initiated. Titres were maintained at similar or higher levels throughout the remainder of the study (Fig. 1). There was no detectable binding of CCK in any of the 11 samples assayed from two control animals.

\subsection{Patterns of feeding behaviour}

Mean daily food intakes were higher $(P<.001)$ during periods of long daylength than during short daylength (Fig. $2 \mathrm{a})$, and this was generally reflected in increases $(P<.001)$ in mean liveweight during the periods of long daylength (Fig. 2b).

The higher mean daily intakes during periods of long daylength were a function of longer mean meal duration (maximum - August: 20.5 min; minimum - December: $16.3 \mathrm{~min}$; S.E.D. $=0.758 ; P<.001)$, shorter intermeal intervals (minimum - August: 38.8 min; maximum - December: $60.4 \mathrm{~min}$; S.E.D. $=3.43 ; P<.001)$. Together, these seasonal differences resulted in a greater number of meals

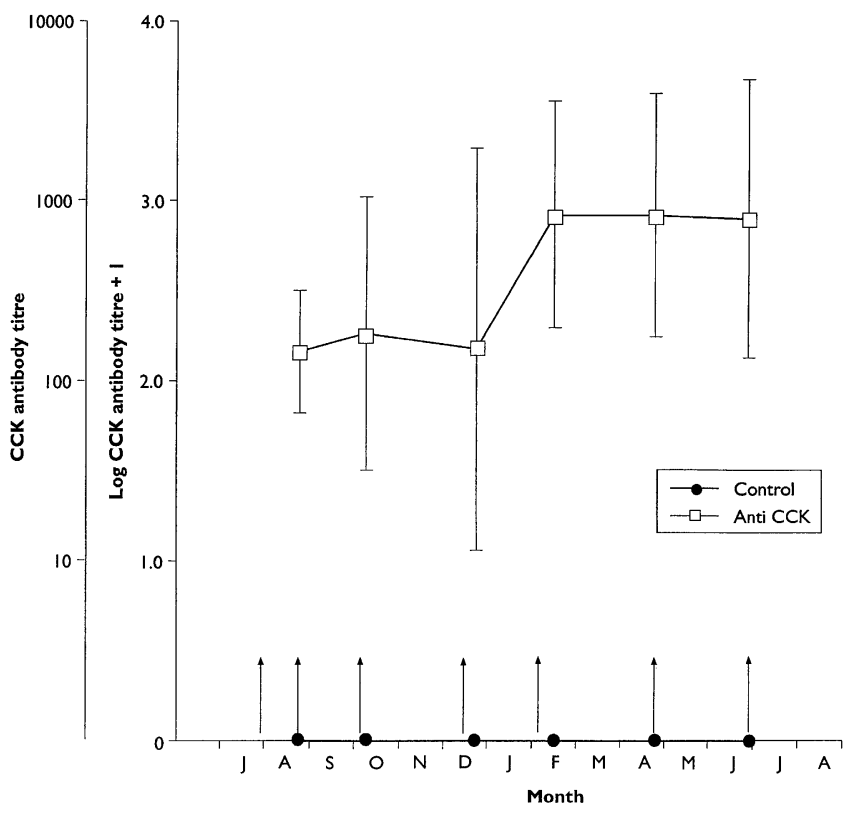

Fig. 1. Mean ( \pm S.E.M.) antibody titres in deer immunised $(\uparrow)$ against CCK $(\square)$ or against the carrier vehicle $(\bullet)$.

per hour during long daylength periods (maximum August: 1.01 ; minimum: December: 0.77; S.E.D. $=0.047$; $P<.001)$ and a greater percentage of the time spent eating (maximum - August: 34.7; minimum - December: 20.8; S.E.D. $=1.76 ; P<.001)$. The mean rate of food ingestion $(\mathrm{g} /$ $\mathrm{min}$ ) also exhibited marked seasonal variation (maximum September: 8.25; minimum - April: 5.13; S.E.D. $=0.401$; $P<.001)$ and this, in conjunction with the pattern of meal duration, resulted in larger mean meal sizes $(\mathrm{g} / \mathrm{meal})$ during long day photoperiods (maximum - September: 154; minimum - April: 86.3; S.E.D. $=8.55 ; P<.001)$.

Immunisation against $\mathrm{CCK}$ did not significantly affect the overall mean daily feed intake. Neither did it affect the overall mean rate of feed ingestion $(\mathrm{g} / \mathrm{min})$. However, there was a significant interaction $(P<.01)$ between immunisation and month (season), with immunised animals exhibiting higher mean rates of ingestion during October to May but lower mean rates during June to September (Fig. 3), and this was associated with similar trends in mean daily feed intakes. Immunisation did not affect, significantly, meal duration or intermeal interval and consequently, there was no significant difference in the proportion of time spent eating or the number of meals per hour.

\subsection{Hormone profiles}

Differences with season (month) were recorded for several hormones, with maximum mean concentrations generally occurring in summer and concentrations declining to a minimum during autumn/winter. Respective maximum and minimum mean plasma concentrations were: $\log$ (prolactin) $(\mathrm{ng} / \mathrm{ml})$ - July: 2.16 (backtransformed = 145), December: 0.93 (backtransformed $=8.6$ ), S.E.D. $=0.233$, 

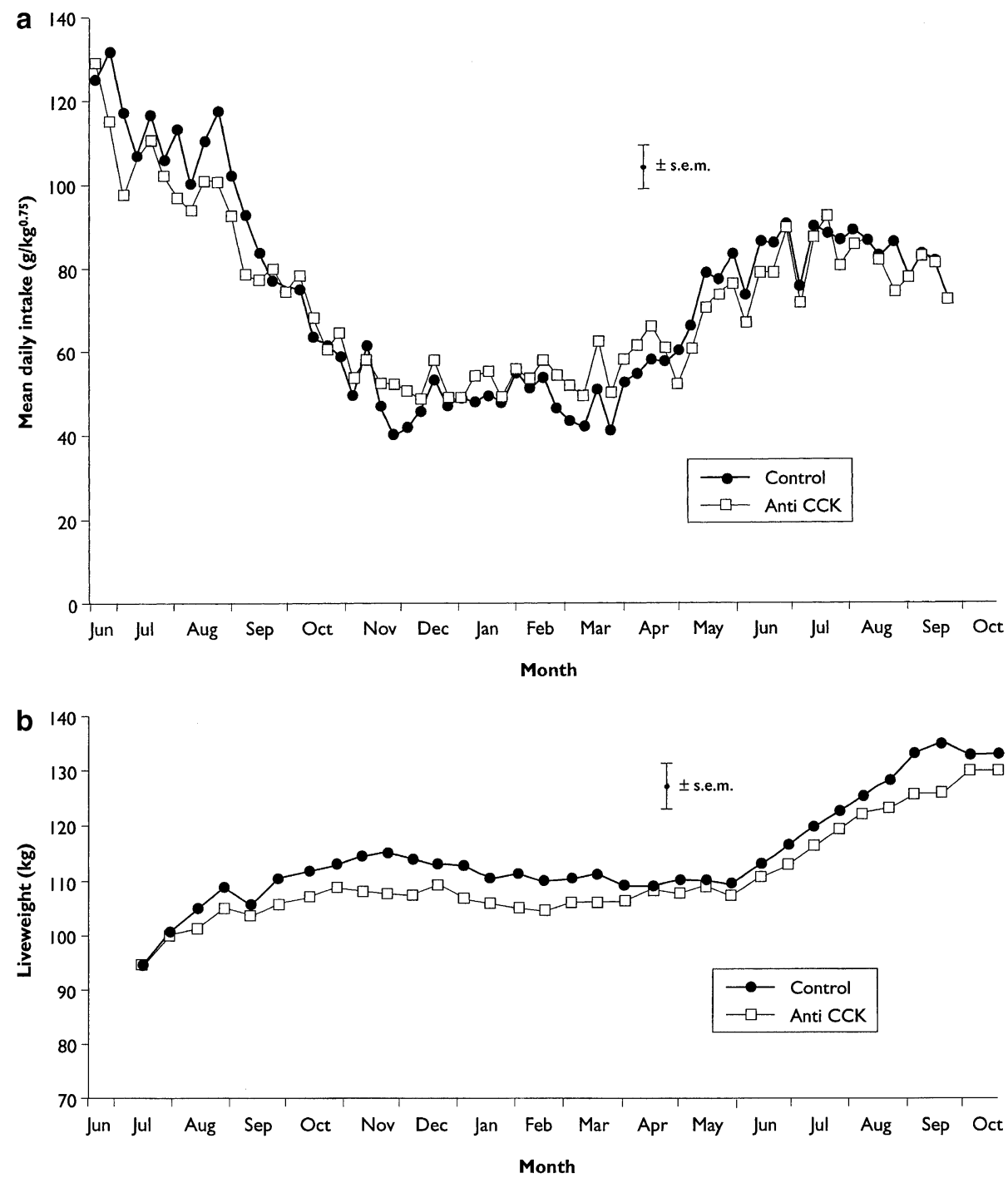

Fig. 2. (a) Mean ( \pm S.E.M.) daily food intakes (fresh weight) and (b) mean liveweights ( \pm S.E.M.) of deer fed ad libitum and immunised against CCK ( $\square$ ) or against the carrier vehicle $(\bullet)$.

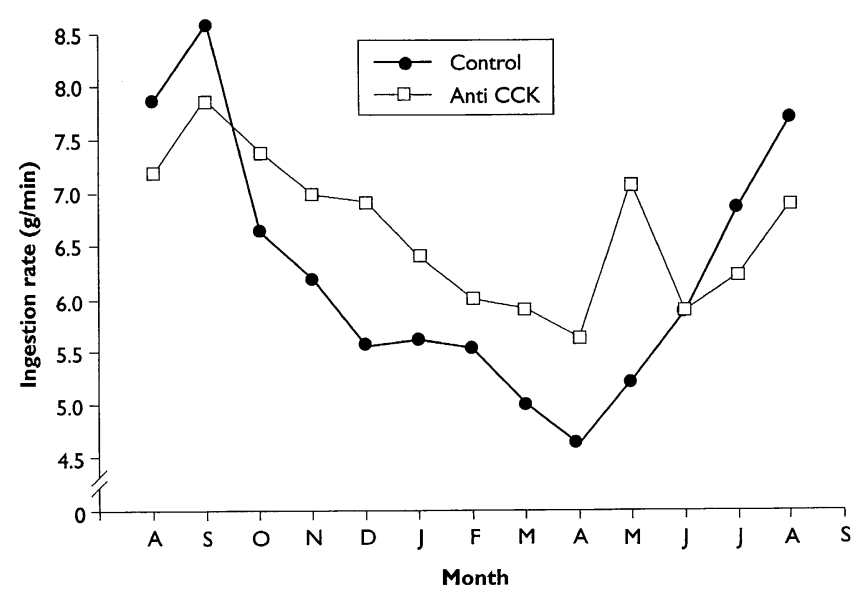

Fig. 3. Mean rates of feed ingestion $(\mathrm{g} / \mathrm{min})$ of deer fed ad libitum and immunised against CCK $(\square)$ or with vehicle solution only $(\bullet)$. S.E.M. for comparison within the same treatment $=0.567$; S.E.M. for Treatment $\times$ Month interaction $=0.812$.
$P<.001 ; \mathrm{T}_{3}(\mathrm{nmol} / \mathrm{l})$ - September: 2.52 , January: 1.54 , S.E.D. $=0.408, P<.001 ; \mathrm{T}_{4}(\mathrm{nmol} / \mathrm{l})-$ June: 108 , August: 75.8; S.E.D. $=18.5, P<.001 ; \log (\mathrm{IGF}-1)-$ July: 2.76 (backtransformed $=575$ ), February: 2.37 (backtransformed $=235)$, S.E.D. $=0.099, P<.001$. There were no consistent seasonal trends in mean plasma concentrations of insulin [mean on log scale: $1.06 \mathrm{mU} / 1$ (backtransformed $=11.5$ ); S.E.D. $=0.105]$ or $\mathrm{GH}$ [mean on log scale: $0.128 \mathrm{ng} / \mathrm{ml}$ (backtransformed $=1.34$ ); S.E.D. $=0.065]$.

None of the hormone profiles recorded was significantly affected by the immunisation treatment, and there were no significant interactions between treatment and season.

\section{Discussion}

Throughout the study, the mean antibody titres recorded in I animals were highly variable but were of a similar order 
to those reported previously in sheep [24] and in pigs, in which significant increases in food intake were induced [17-19]. While the validity of cross-species comparisons is limited, it appears likely that the antibody titres achieved in the present study were sufficient to alter the biological availability of CCK and, potentially, to induce a biological response. The absence of an increase in overall mean daily feed intake in response to the high antibody titres is consistent with the observations of Trout et al. [24] who reported no change in the feed intake of ram lambs immunised against CCK.

Higher mean daily feed intakes were recorded in summer than winter; the apparent reduction in mean intake in the second summer, compared with the first, was largely attributable to the fact that the animals had increased in liveweight by the second summer and the intakes were expressed as a function of liveweight.

Owing to the fact that a complete diet was used in the present study, the dietary energy content was greater than in a high roughage diet. Consequently, the observed seasonal variation in intake may have been less than if the animals had been fed a high roughage diet because higher dietary energy contents are not only associated with lower DM intakes but the reduction is less marked in winter [25] and so the magnitude of the seasonal cycle may be reduced relative to that of animals fed a high roughage diet. Thus, the effects of immunisation against CCK may also be less marked than in roughage-fed animals. However, the underlying physiological control mechanisms are unlikely to be fundamentally altered.

Seasonal variation in daily feed intake in red deer is a function of many different factors including variation in the amount of feed ingested per unit of eating time, meal size, meal duration, intermeal interval, and meal frequency [20]. There was a significant interaction between season and treatment with respect to one of these factors, the rate of feed ingestion during meals. This interaction reflected a marked reduction in the amplitude of the seasonal variation in this parameter in I animals and this was associated with a similar trend in mean daily intake. These results suggest that immunisation against CCK altered feed ingestion rate and, to a lesser extent, daily feed intake, but in a manner that differed with season.

These effects of immunisation were probably a function of altered biological availability of systemic CCK. While both central and peripheral CCK signals could be involved in the regulation of feeding behaviour and daily feed intake, since the CCK receptors in the brain are not involved in mediating responses to exogenous CCK [2] and it is thought unlikely that this hormone can cross the bloodbrain barrier $[5,10]$, the effects on eating pattern of manipulation of CCK profiles in the peripheral circulation are probably mediated via the liver, the vagus nerve, and CCK binding sites within the nerve [6]. The possibility that paracrine actions of CCK in the gut were also affected cannot be ruled out although this would depend on the extent to which antibodies could enter the target tissues; this may be very limited in view of the large size of the molecules involved.

Since the effect of immunisation was found to differ with season, it is likely that CCK does not act alone, i.e., expression of the effects of season probably involves interaction between CCK and other hormones and/or their receptors, which exhibit seasonal variation. The profiles of the thyroid hormones, IGF-1, and prolactin exhibited changes with season and so these hormones could have a role in the expression of seasonal changes in feeding behaviour and feed intake. While measurements were of insufficient frequency to fully characterise GH profiles, owing to the pulsatile nature of its secretion, the sampling regime was probably adequate to detect gross changes with season, if they were present. The absence of a significant treatment difference in the profiles of any of the hormones exhibiting seasonal variation suggests that rate of feed ingestion was not mediated directly through changes in profiles of these hormones and that manipulation of CCK availability, by immunisation, did not alter the profiles. However, the possibility remains that the seasonal changes in one or more of these hormone profiles have a permissive role and that they induce a change in sensitivity of the appetite centre to CCK.

It is known that the sensitivity of the appetite centre to the inhibitory effects of CCK depends, at least in some species, on the concentration of insulin in the brain $[7,8$, 22]. There was no evidence of a large seasonal change in mean circulating insulin concentrations, the main source of intracerebral insulin [4]. While the possibility remains of seasonal differences in the rate of transfer of insulin into the brain [23], previous studies on seasonal ruminants suggest that this is unlikely [21]. However, seasonal differences in $T_{3}$ profiles could alter the pattern of insulin delivery to the liver through the portal vein without change in peripheral concentrations [1], and these in turn could alter neural feedback to the appetite centre from the liver. Further work is required to determine the potential significance of such regulatory mechanisms with respect to seasonality of feed intake.

In summary, the results of the present study suggest that CCK has a role in the expression of seasonal variation in the rate of feed ingestion during meals in ruminants, but is not directly involved in the expression of seasonal changes in meal size or duration. The effect of CCK on the appetite centre appears to be complex and not directly related to circulating hormone profiles, but may nevertheless depend on an interaction between $\mathrm{CCK}$ and seasonal changes in some of these hormones.

\section{Acknowledgments}

The work was funded by the Scottish Executive Rural Affairs Department. 


\section{References}

[1] Achmadi J, Terashima Y. The effect of propylthiouracil-induced low thyroid function on secretion response and action of insulin in sheep. Domest Anim Endocrinol 1995;12:157-66.

[2] Brenner LA, Ritter RC. Intracerebroventricular cholecystokinin A receptor antagonist does not reduce satiation by endogenous CCK. Physiol Behav 1998;63:711-6.

[3] Bruce LA, Atkinson T, Hutchinson JSM, Shakespear RA, MacRae JC. The measurement of insulin-like growth factor I in sheep plasma. J Endocrinol 1991;128:R1-4.

[4] Coker GTI, Stuselska D, Harmon S, Burke W, O’Malley KL. Analysis of tyrosine hydroxylase and insulin transcripts in human neuroendocrine tissues. Mol Brain Res 1990;8:93-8.

[5] Della-Ferra MA, Baile CA. Cholecystokinin octapeptide. Continuous picomole injections into the cerebral ventricles of sheep suppress feeding. Science 1979;206:471-3.

[6] Farningham DAH, Mercer JC, Lawrence CB. Satiety signals in sheep : involvement of CCK, propionate, and vagal CCK binding sites. Physiol Behav 1993;54:437-42.

[7] Figlewicz DP, Sipols AJ, Seeley RJ, Chavez M, Woods SC. Intraventricular insulin enhances the meal-suppressive efficacy of intraventricular cholecystokinin octapeptide in the baboon. Behav Neurosci 1995;3:567-9.

[8] Figlewicz DP, Stein LJ, West D, Porte D, Woods SC. Intracisternal insulin alters sensitivity to CCK-induced meal suppression in baboons. Regul Integr Comp Physiol 1986;19:R856-60.

[9] Forbes JM. Voluntary feed intake and diet selection in farm animals. Oxon, UK: Wallingford CAB International, 1997.

[10] Grovum WL. Cholecystokinin administered intravenously did not act directly on the central nervous system or on the liver to suppress food intake of sheep. Br J Nutr 1981;45:183-201.

[11] Kay RNB. Seasonal changes of appetite in deer and sheep. Agric Res Counc Res Rev 1979;5:13-5.

[12] Kay RNB, Staines BW. The nutrition of the red deer (Cervus elaphus). Nutr Abstr Rev 1981;51:601-22.

[13] Lawes Agricultural Trust. Genstat 5 Committee. Genstat 5 release 3 reference manual. Oxford: Clarendon Press, 1994.
[14] Loudon ASI, Milne JA, Curlewis JD, McNeilly AS. A comparison of seasonal changes and patterns of growth, voluntary feed intake and reproduction in juvenile and adult red deer (Cervus elaphus) and Pere David's deer (Elaphurus davidianus) hinds. J Endocrinol 1989;122:733-45.

[15] McNeilly AS, Andrews P. Purification and characterisation of caprine prolactin. J Endocrinol 1974;60:359-67.

[16] MacRae JC, Bruce LA, de Hovell FDB, Hart IC, Inkster J, Atkinson $\mathrm{T}$. Influence of protein nutrition on the response of growing lambs to exogenous bovine growth hormone. J Endocrinol 1991;130:53-61.

[17] Pekas JC. Effect of cholecystokinin immunisation, enhanced food intake and growth of swine on lean yield and carcase composition. J Nutr 1991;121:563-7.

[18] Pekas JC, Trout WE. Stimulation of food intake and growth of swine by cholecystokinin immunisation. Growth Dev Aging 1990; 54:51-6.

[19] Pekas JC, Trout WE. Cholecystokinin octapeptide immunisation: effect on growth of barrows and gilts. J Anim Sci 1993;71: 2499-505.

[20] Rhind SM, McMillen SR, Duff E, Hirst D, Wright S. Effects of season and level of food intake on possible hormonal determinants of appetite in red deer (Cervus elaphus). Physiol Behav 1998;65:295-302.

[21] Rhind SM, McMillen SR, Duff E, Kyle CE, Wright S. Seasonality of food intake in soay sheep and the roles of seasonal and circadian hormone profiles in appetite regulation. Physiol Behav 2000;71: $343-51$.

[22] Riedy CA, Chavez M, Figlewicz DP, Woods SC. Central insulin enhances sensitivity to cholecystokinin. Physiol Behav 1995;58: $755-60$.

[23] Schwartz MW, Figlewicz DP, Baskin DG, Woods SC, Porte D. Insulin in the brain: a hormonal regulator of energy balance. Endocr Rev 1992;13:387-414.

[24] Trout WE, Pekas JC, Schanbacher BD. Immune, growth and carcass responses of ram lambs to active immunisation against desulfated cholecystokinin (CCK-8). J Anim Sci 1989;67:2709-14.

[25] Webster JR, Corson ID, Littlejohn RP, Masters BM, Suttie JM. Effect of diet energy density and season on voluntary dry matter and energy intake in male red deer. Anim Sci 2000;70:547-54. 